\title{
In vitro Study on Hepatitis B Virus Infecting Human Choriocarcinoma JEG3 Cells and Its Mechanism
}

\author{
Yang Ding $^{\mathrm{a}}$ Li Ma $^{\mathrm{a}}$ Xin-zhu Wang ${ }^{\mathrm{c}}$ Jian Zhang ${ }^{\mathrm{d}}$ Gui-zhen Zhao ${ }^{\mathrm{b}}$ \\ Zhao-quan Wang ${ }^{b}$ Xiao-guang Dou $^{b}$ \\ a Infectious Disease Laboratory and ' Infectious Disease Department of Shengjing Hospital, \\ China Medical University, Shengjing, ${ }^{c} 463$ Hospital of Shenyang Air Force, Shenyang, and ${ }^{\mathrm{d}} 3 \mathrm{rd}$ People Hospital \\ in PanJing, Liaoning, China
}

\section{Key Words}

Hepatitis B · JEG3 - Placenta trophoblast - Infection •

Southern blot $\cdot$ Real-time PCR

\section{Abstract}

Aim: To build a hepatitis B virus (HBV)-infected human trophoblast cell model in vitro and determine the mechanism of intrauterine HBV infection. Methods: Serum from hepatitis B-infected patients containing HBV DNA $>10^{9}$ was drawn, subsequently inoculated into human trophoblast cells in vitro (JEG3) and passage-cultured. The supernatants and intracellular HBV viral load of inoculated cells were tested by realtime PCR, and HBV DNA was determined by Southern blot. Results: From inoculation of the 1st passage JEG3 cells, the supernatant viral load of the 1st passage was seen increasing over time, which peaked at $120 \mathrm{~h}$, whereas the HBV viral load was seen decreasing gradually in subsequent passages, and tested negative after the 6th passage. In addition, infected cells of HBV DNA were tested by Southern blot, and showed continual expression in the subsequent cell passages 1-5 while passage 6 was negative. HBsAg was tested as positive from different passages $1-5$, and its concentration was also seen decreasing with each subsequent passage cultured until the 6th passage when it tested negative. Conclusion: HBV could infect human trophoblast cells (JEG3) in vitro, and it showed continual expression in subsequent cell passages $1-5$.

Copyright $\odot 2011$ S. Karger AG, Basel

\section{Introduction}

Hepatitis B is a global epidemic disease which poses significant dangers to human health [1]. China is a country with a high reported incidence of hepatitis $B$ virus (HBV) infection, with about 120 million people carrying $\mathrm{HBV}$. Over the years, prevention of HBV infection made a step forward when combined hepatitis $B$ vaccines and hepatitis B immunoglobulin was introduced [2-5]; however, there are still vertical transmissions occurring at a reported rate of 5-15\% each year [6]. Vertical transmission is one of the main routes of HBV transmission [7-9], while intrauterine transmission is a major factor which has resulted in the most HBV carriers, i.e. mother-tochild transmission.

\section{KARGER}

Fax +4161306 1234

E-Mail karger@karger.ch

www.karger.com
(C) 2011 S. Karger AG, Basel

$0300-5526 / 11 / 0545-0276 \$ 38.00 / 0$

Accessible online at:

www.karger.com/int
$\mathrm{Ma} \mathrm{Li}$

Infectious Disease Laboratory of Shengjing Hospital, China Medical University

No. 36, San Hao Street, He Ping District

Shenyang City, Liaoning Province 110004 (China)

Tel.+8624966156 2033, E-Mail mal12007@sina.com 
Currently, the mechanism of intrauterine transmission has not yet been fully understood. Some researchers have studied the theory of placental infection and discovered that HBV could infect placental tissue $[10,11]$. Hence, in vitro models of $\mathrm{HBV}$ infection have been our focus of study to date. Through utilization of a choriocarcinoma cell lines, JEG3, we have built an in vitro cellular model of HBV-infected placental trophoblast to aid us in observing the nature of viral infection in vitro in order to provide a laboratory basis for our study on HBV intrauterine transmission [12].

\section{Materials and Methods}

\section{Reagents}

Cell culture media, DME/F12 1:1 culture medium (Hyclon Inc.); fetal bovine serum (American Gibco Inc.); trypsin and antibiotics (penicillin and streptomycin, American Sigma Inc.); ELISA kit (Shanghai Kehua Bioengineering Co. Ltd.); anti-mouse $\mathrm{HBsAg}$, anti-rabbit $\mathrm{HBcAg}$ and SP immunohistochemistry kit (Beijing Zhong Shan Bio Co.); HBV DNA $>10^{9}$ copies $/ \mathrm{ml}$ serum obtained from patients of our hospital; cell lysis buffer (Beyotime Institute of Biotechnology, Beijing); proteinase K (American Sigma Inc.); Virus DNA kit (Tiangen Biotech Beijing Co.); and realtime PCR primer, Southern blot probe primer and amplification reagent (Takara Biotechnology Dalian Co. Ltd.) were used.

\section{JEG3 Cells and Cell Culture}

JEG3 cell lines were obtained from Shanghai Institute of Cell Biology. The JEG3 cell culture DME/F12 1:1 culture solution (containing 12\% fetal bovine serum, $100 \mathrm{U} / \mathrm{ml}$ penicillin, streptomycin, $\mathrm{pH}$ 7.4) was placed in an incubator under $5 \% \mathrm{CO}_{2}$ and $95 \%$ air atmosphere saturated humidity at $37^{\circ}$. When cell density reached higher than $90,0.25 \%$ trypsin was used to digest passaged cells.

\section{JEG3 Cells and HBV Infection}

JEG3 cells were infected by HBV and were passage-cultured until cell density reached $70-80 \%$, at which time the culture solution was discarded, replaced with serum-free DME/F12 1:1 culture solution, and sterile $\mathrm{HBV}(+)$ serum was added against 100 DNA/cell concentration. The culture was then mixed gently, spread evenly onto cell surfaces and incubated at $37^{\circ}$ for $24 \mathrm{~h}$. The infected fluid was then assimilated, washed with $0.01 \mathrm{mmol} / \mathrm{l} \mathrm{pH}$ 7.4 PBS for 8 cycles. The 8th cycle wash solution was then collected (HBsAg test should be negative), and then culture solution containing $12 \%$ fetal bovine serum was added to resume culturing. Culture solution at 24-, 48-, 72-, 96- and 120-hour intervals was collected, passage-cultured and assimilated for each passage of their infected cells, supernatant and cell slide $(0.01 \mathrm{mmol} / \mathrm{l}$ PBS washed, $4 \%$ paraformaldehyde fixation, stored at $\left.-80^{\circ}\right)$. For cellular DNA extraction, collected cells were resuspended with 0.01 $\mathrm{mmol} / \mathrm{l} \mathrm{PBS}$ and centrifuged, the supernatant was discarded and cell lysis buffer was subsequently added, digested with proteinase $\mathrm{K}$, extracted with phenol-chloroform-isoamyl alcohol and then

HBV Infecting Human Choriocarcinoma

JEG3 Cells washed with ethanol. DNA precipitation was then dissolved using sterile deionized water and stored at $-80^{\circ}$. The collected cell supernatant then underwent DNA extraction using viral DNA extraction fluid.

\section{Real-Time Fluorescent Quantitative PCR}

HBV DNA Fluorescent Quantitative Detection. A specific primer designed as an HBV S-gene region primer was as follows: upstream primer-F, 5'-CGAATCTTTCTGTTCCCAATCC-3' (nt 68-89); downstream primer-R: 5'-AATGCTCCCGCTCCTACCT-3' [nt 197-215; designed by Takara Biotechnology (Dalian)]. The PCR product size was $148 \mathrm{bp}$. A standard curve was plotted based on HBV plasmid, the real-time PCR amplification curve and melt curve were determined at the end of the reaction, and the experimental results were analyzed by plotting a standard curve. Meanwhile, HBV DNA fluorescent quantitative PCR assay reagent (product of Shenzhen PG Biotechnology Co. Ltd.) was used for comparison testing [13].

HBV DNA Real-Time Fluorescent Quantitative PCR Assay. DNA was taken from cells and supernatants as templates, and HBV DNA was assayed respectively using our designed primer and quantitative reagents of PG Biotech's HBV DNA fluorescent quantitative reagents. The total reaction volume was $25 \mu \mathrm{l}$. The reaction condition was set at $95^{\circ}$ for $10 \mathrm{~s}, 95^{\circ}$ for $5 \mathrm{~s}, 60^{\circ}$ for $20 \mathrm{~s}$ for 40 cycles, and a melting curve was plotted at $65^{\circ}$ for $15 \mathrm{~s}$; and $94^{\circ}$ for $2 \mathrm{~min}, 94^{\circ}$ for $30 \mathrm{~s}, 55^{\circ}$ for $45 \mathrm{~s}$ for 40 cycles. The $\mathrm{CT}$ value was recorded, HBV DNA plasmid was taken as a template, a standard curve was plotted and viral load was calculated from the standard curve obtained.

\section{HBV DNA Southern Blot}

For HBV DNA Southern blot detection, the HBV gene sequence GI:21326584 to design $\mathrm{P}^{32}$ probe primer was used: primer P1, 5'-ACTCGTGGTGGACTTCTC-3'; and P2, 5'-CCGTGCTGGTAGTTGATG-3' (nt 338-356). The PCR product size was $258 \mathrm{bp}$.

Supernatant HBsAg and HBeAg ELISA Assay of Infected Cells HBsAg and HBeAg ELISA assay was performed on supernatants at each postinfection interval as well as in each passage, and a noninfected cell culture solution was used as a blank control. The sample OD value was 2.1 times higher than that of the negative control, which was interpreted as positive and vice versa.

\section{Immunohistochemical Detection of $\mathrm{HBs} \mathrm{Ag}$ and $\mathrm{HBcAg}$}

Expressions of Each Cell Passage

Fixated cell slides were washed with $0.01 \mathrm{~m} \mathrm{~mol} / \mathrm{l}$ PBS 3 times for $3 \mathrm{~min} /$ wash and endogenous enzymes were inactivated with $3 \% \mathrm{H}_{2} \mathrm{O}_{2}$. They were blocked with blocking buffer, primary antibody was added and they were kept at $4^{\circ}$ overnight. Products were washed with $0.01 \mathrm{~m}$ PBS 3 times for $3 \mathrm{~min} / \mathrm{wash}$, followed by the addition of egg albumin and bio-horseradish peroxidase conjugate, respectively, placed at $37^{\circ}$ for $15 \mathrm{~min}$, and washed with 0.01 $\mathrm{mmol} / \mathrm{l}$ PBS 3 times for $3 \mathrm{~min} / \mathrm{wash}$. A negative control was designed. Specimens were stained with $\mathrm{DAB}$ and subsequently with hematoxylin. Products were then treated with a gradient alcohol dehydration DMB coverslip using Permount. Obtained specimens were then observed under a light microscope and photographed. 


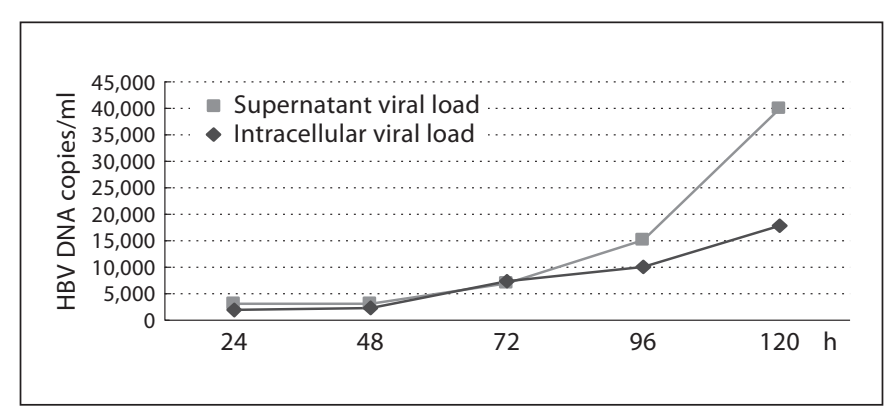

Fig. 1. Intracellular and supernatant HBV DNA load of 1st-passage cells after infection at different time intervals.

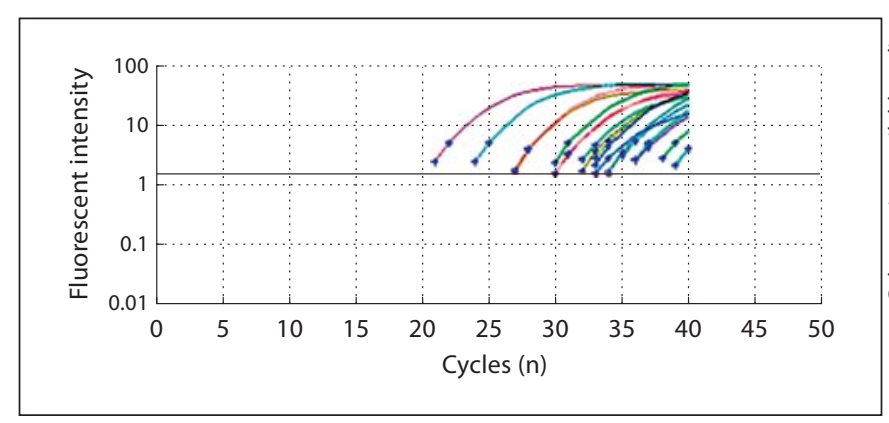

Fig. 3. Amplification curve of supernatant and cellular sample $\mathrm{HBV}$ viral load of each passage cells after infection.

\section{Results}

HBV DNA Quantitative Assays of JEG3 Primary Cells Comparison testing results were obtained from our laboratory setups as well as PG reagents, which were basically identical. The DNA extracted from cells and the supernatants at variable time intervals after $\mathrm{HBV}$ infection of JEG3 primary cells were assayed by HBV DNA fluorescent quantitative PCR. The supernatant and intracellular HBV viral loads at each time interval showed an increasing trend over time (fig. 1).

\section{HBV DNA Quantitative Assays of JEG3 1st through 10th Passage Cells}

The infected cells were passage-cultured (1st through 10th passage, approx. every $96 \mathrm{~h}$ each subsequent passage), and the cultured cells and supernatants were collected at each passage, had their DNA extracted and were run through HBV DNA fluorescent quantitative PCR amplification assay. Cells were passage-cultured after being infected with HBV, and the HBV viral load of cells and

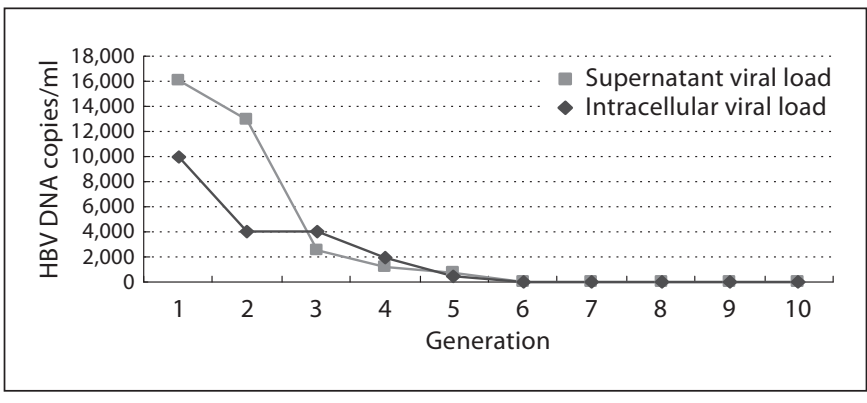

Fig. 2. Intracellular and supernatant $H B V$ DNA load at the 1st through 10th passage of JEG3 cells after infection.

supernatants at each passage was obtained. Both showed gradual decrement over the passages until the 6th passage when the HBV viral load was shown to be absent (fig. 2).

The HBV DNA quantitative PCR sample amplification curve can be seen in figure 3 , the log-concentration can be seen in figure 4 and the amplification curve of the standard sample can be seen in figure 5. Real-time PCR product electrophoresis (148 bp) can be seen in figure 6 .

\section{HBV DNA Southern Blot of JEG3 1st through 6th Passage Cells}

HBV DNA was obtained from JEG3 1st through 5th passage cells. Both showed gradual decrement over passages until the 6th passage when HBV viral load was shown to be absent (fig. 7).

\section{Supernatant HBsAg and HBeAg Detection in Infected Cells}

Supernatant HBsAg concentration in the early passages of infected cells was shown to increase over time (fig. 8), whereas $\mathrm{HBeAg}$ were all negative. Supernatant $\mathrm{HBsAg}$ could be detected in the primary to the 5 th passages of cultured cells, and its concentration was shown to decrease over passages, becoming totally absent during the 6th passage (fig. 9). Supernatant HBeAg were shown to be negative in all cell passages.

\section{HBsAg and HBcAg Expression in Each Cell after Infection}

The SP immunohistochemistry technique was used to assay cell slides cultured at the 1st, $2 \mathrm{nd}$, 3rd, 4 th and 5 th passages. During the 1st, 2nd, 3rd, 4th and 5th cell passages, in terms of HBsAg staining, brownish-yellow stains that were disseminated over the cytoplasm could be seen and assumed as positive. In terms of $\mathrm{HBcAg}$ staining, in the 1st, 2 nd, 3rd, 4 th and 5 th infected cell pas- 
Fig. 4. Log values of the HBV DNA standard sample initial copies.

Fig. 5. Amplification curve of the $\mathrm{HBV}$ DNA standard sample.

Fig. 6. JEG3 (1st through 7 th passage after infection) supernatant (1-7) and cell (814) HBV DNA real-time PCR product electrophoresis (148 bp); (-) denotes normal cells, $\mathrm{M}$ denotes DNA maker.

\begin{tabular}{lr}
\hline Y-axis & 46.96 \\
\hline Intercept & -3.77 \\
\hline Gradient & 0.012 \\
\hline $\begin{array}{l}\text { Error } \\
\text { correlation }\end{array}$ & -0.998 \\
coefficient & \\
\hline
\end{tabular}
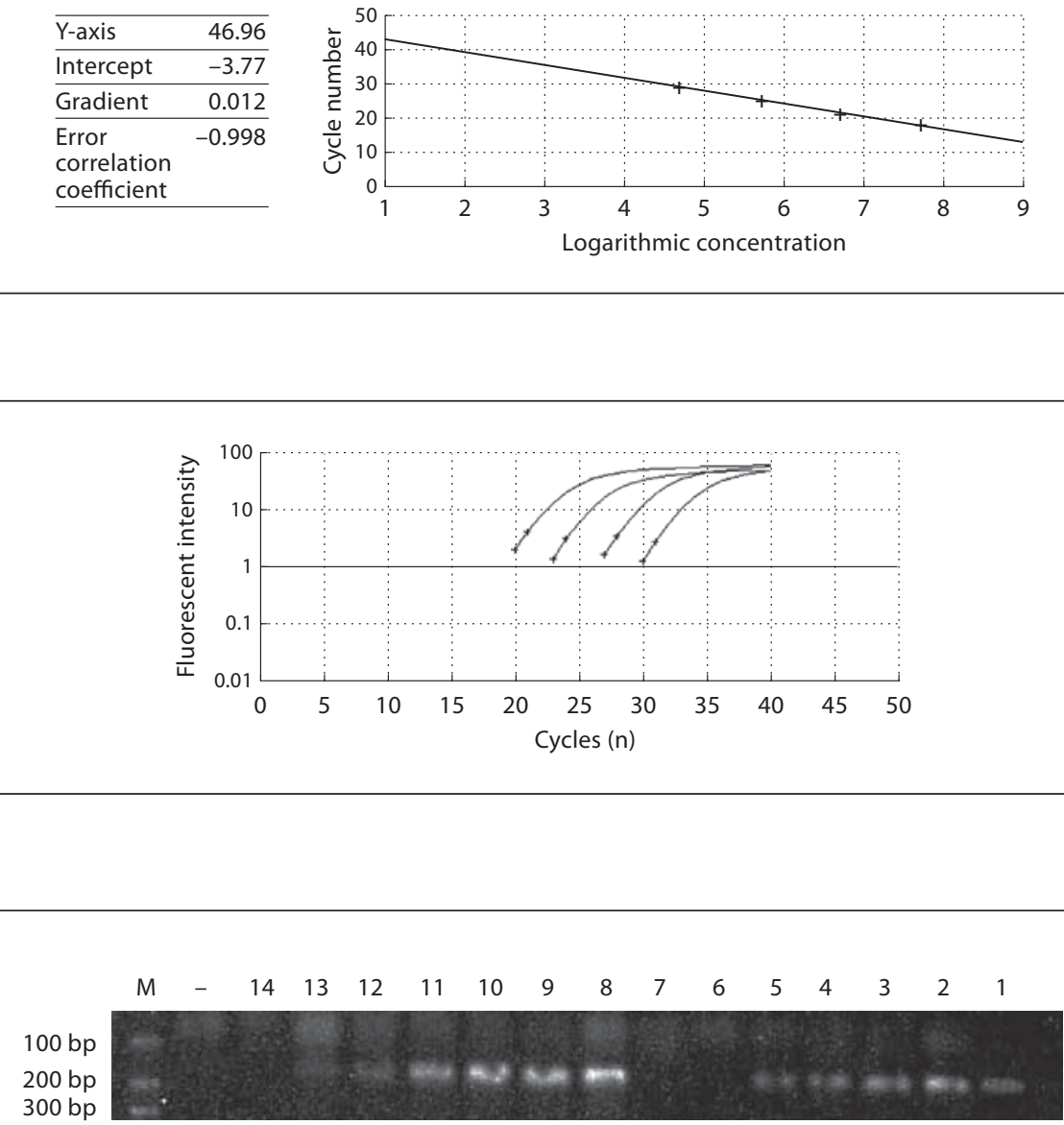

$200 \mathrm{bp}$

$300 \mathrm{bp}$

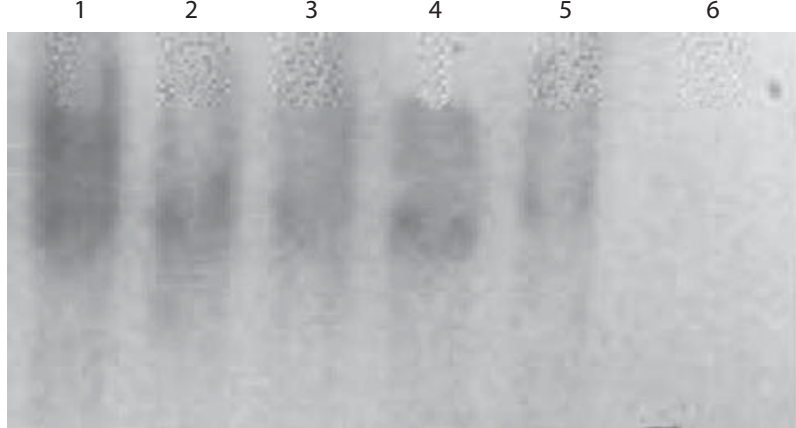

Fig. 7. JEG3 (1st through 6th passage after infection) cell (1-6) HBV DNA Southern blot.

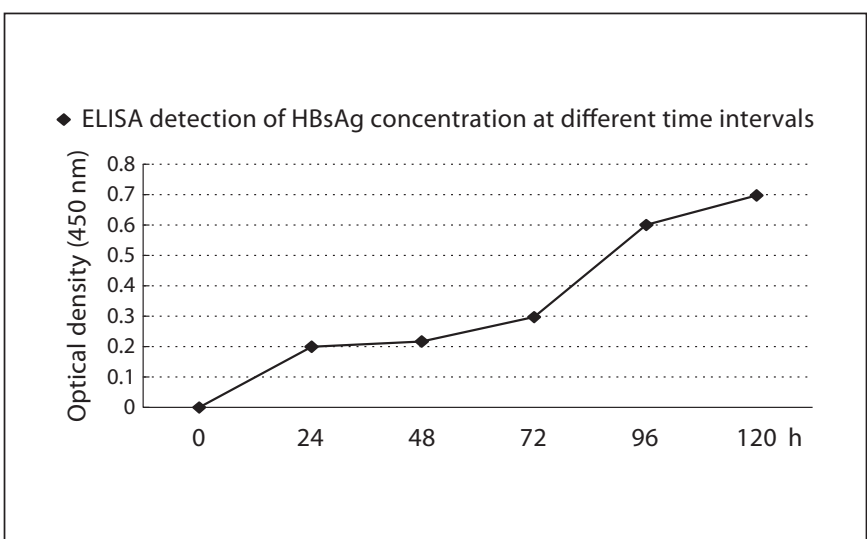

Fig. 8. Supernatant HBsAg concentration of 1st-passage-infected JEG3 cells at different time intervals. 
Fig. 9. Supernatant HBsAg concentration in infected cells at each passage culture.
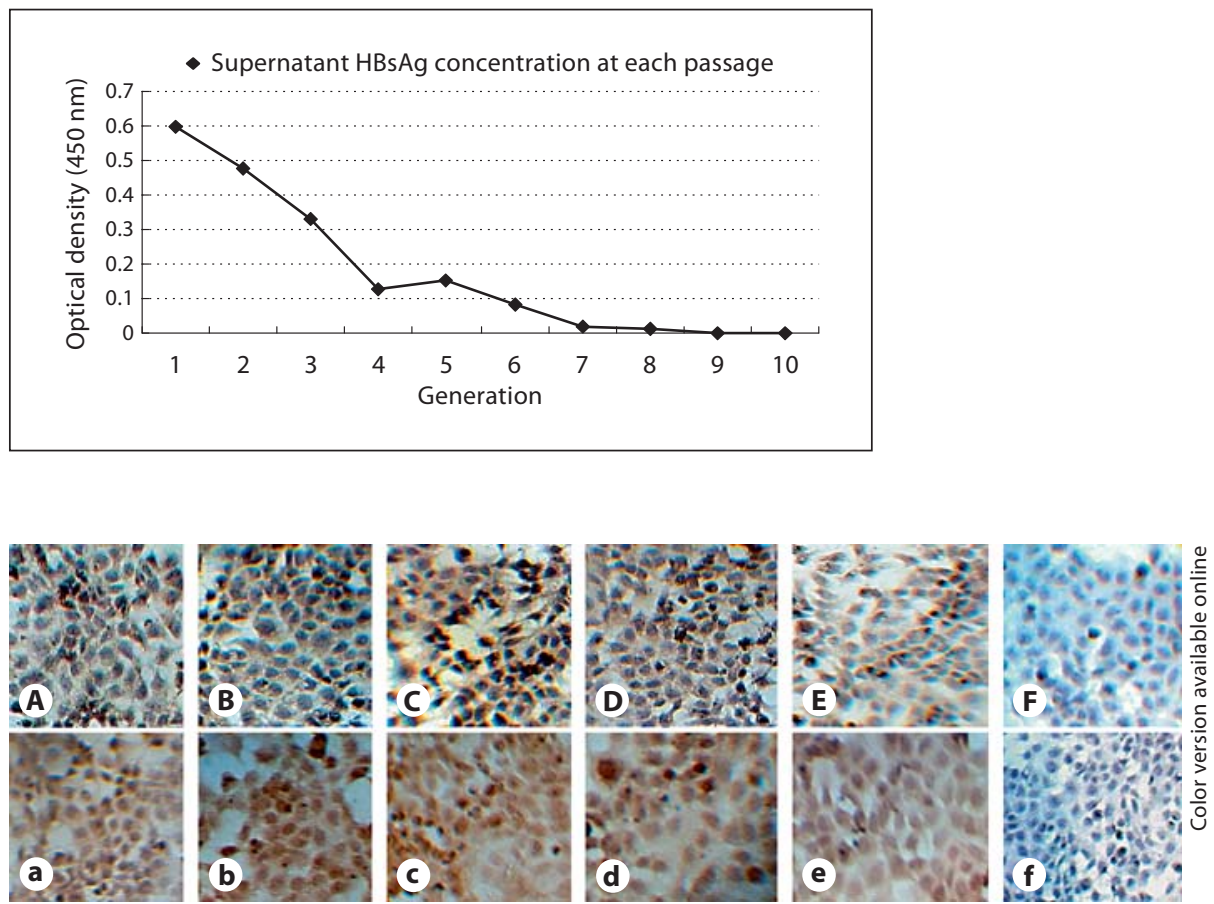

sages, nuclei stained brownish-red were seen and assumed as positive, whereas negative results were shown in both normal cultured cells (fig. 10).

\section{Discussion}

Even though HBV is a hepadnavirus, recent studies have suggested that the majority of viruses lead to placental infection, which then affects the fetus [14]. Some virus varieties can penetrate the placental barrier and travel into the body of a fetus [15]. In 1988, Lucifora et al. [16] discovered the presence of HBsAg in the placenta of a $\mathrm{HBs} A g$-carrier gravida. In later studies, some researchers further proved the presence of HBV throughout all the histological layers of the placenta. The placental barrier is mainly made up of trophoblast cells, capillary endothelial cells and basement membrane. Trophoblast cells are located at the outermost layer, immersed in maternal blood directly. Therefore, the high viral load in maternal blood is the crucial part of HBV infection on a trophoblast cell. Hence, the role of trophoblast cells in intrauterine viral transmission should not be neglected [17-20].

In 2001, Gabrielli et al. [21] reported on in vitro culturing of trophoblast cells and discovered that viruses could infect trophoblast cells under in vitro conditions. Our study showed HBV-infected trophoblast cells in vitro, the release of HBsAg concentration and HBV load gradually increasing over time. Additionally, they were all positively correlated with each other, while intracellular HBV load was also shown to be increasing. This shows that HBV is able to infect trophoblast cells, and its viral load expression shows an increasing trend over a certain period of time. This fully demonstrated that, after $24 \mathrm{~h}$ of HBV infection, viruses are removed from cell surfaces through multiple rinses in general, but only the replication of HBV which has entered the cells may result in viral load and its secreted HBsAg increasing over time.

In 1986, Sureau et al. [22] reported that the use of closed-loop HBV DNA-infected hepatoma cell lines in vitro may promote the reproduction of intracellular HBV. However, the adoption of a transfection technique cannot mimic the natural infection status of HBV in terms of the regulatory effects of HBV towards cell membrane, infection process, cell-associated factors, etc. These have not yet been resolved. An HBV genome with a unique structure, the $S$ gene in the $S$ zone on the L chain (nt 155-835), transcribes and encodes HBsAg major protein under the control of the $\mathrm{S}$ gene promoter. The $\mathrm{C}$ gene promoter, $\mathrm{CP}(\mathrm{nt} 1643-1849)$, is the key regulating factor of HBV's replication and guides the transcription of 3.4- and 3.5$\mathrm{kb}$ mRNA.

Some researchers have assumed that the structural integrity of HBV, particularly the high expression pre-S1 
protein as well as regulatory factors required for viral replication, HBsAg concentration, etc., are the factors which promote the success of $\mathrm{HBV}$ infection into cultured cells in vitro [23]. HBV covalently closed-loop DNA (cccDNA) is the synthetic template of intermediate mRNA and pregenome RNA in HBV genome replication, and is a key factor which leads to persistent HBV infection [24-27]. In order to justify the presence of $\mathrm{HBV}$ replication in placental trophoblast cells, it is necessary to perform HBV cccDNA detection during the construction of the in vitro HBV-infected trophoblast cell model on which we are currently concluding this corresponding study. With the joint efforts of all researchers, we believe that these stud- ies will present useful evidence for science and provide us with a better understanding of the mechanisms of intrauterine $\mathrm{HBV}$ infection.

\section{Acknowledgements}

This report was supported by the Nation ' 95 ' Important Topics of National Natural Science Fund Committee, China (96906-0303) and Correlation Study on Immune Escape of HBV P/S Genovariation with HBV Intrauterine Transmission, National Natural Science Fund Committee, China (30972612). We thank all members of Blood Research Laboratory of Shengjing Hospital, China Medical University for their technological assistance.

\section{References}

$\checkmark 1$ Maddrey WC: Hepatitis B: an important $>_{11}$ Bai H, Zhang L, Ma L, Dou XG, Feng GH, public health issue. Med Virol 2000;61:362366.

2 Ma Li, Wang Zhao-Quan, Zhao Gui-Zhen, Liang Zheng-Lun, Wang Xin-Zhu: Load of HBV DNA in serum and breast milk of HBV carried mother and safety of breast-fed infants. China J Mod Med 2007;17:2433-2436.

-3 Zuckerman JN: Hepatitis B immune globulin for prevention of hepatitis B infection. J Med Virol 2007;79:919-921.

4 Van Herck K, Van Damme P: Benefits of early hepatitis B immunization programs for newborns and infants. Pediatr Infect Dis J 2008;27:861-869.

$\checkmark 5$ Habib S, Shaikh OS: Hepatitis B immune globulin. Drugs Today (Barc) 2007;43:379394.

$\checkmark 6$ Michielsen PP, Van Damme P: Viral hepatitis and pregnancy. Acta Gastroenterol Belg 1999;62:21-29.

7 Gambarin-Gelwan M: Hepatitis B in pregnancy. Clin Liver Dis 2007;11:945-963, x.

-8 Xu DZ, Yan YP, Choi BC, Xu JQ, Men K, Zhang JX, Liu ZH, Wang FS: Risk factors and mechanism of transplacental transmission of hepatitis B virus: a case-control study. J Med Virol 2002;67:20-26.

$>9$ Kwon CI, Hwang SG, Shin SJ, Chang SW, Kim SY, Ko KH, Hong SP, Park PW, Rim KS, Kang MS, Chung HJ, Hong SP: Occult hepatitis $\mathrm{B}$ virus infection in pregnant woman and its clinical implication. Liver Int 2008; 28:667-674.

10 Xu DZ, Yan YP, Zou S, et al: Role of placental tissues in the intrauterine transmission of hepatitis B virus. Am J Obstet Gynecol 2001; 185:981-987. Zhao GZ: Relationship of hepatitis B virus infection of placental barrier and hepatitis B virus intra-uterine transmission mechanism. World J Gastroenterol 2007;13:3625-3630.

12 Chang $\mathrm{MH}$ : Hepatitis B virus infection. Semin Fetal Neonatal Med 2007;12:160-167.

13 Ma L, Zhao G: Comparative Study of RQ-PCR and ELQ-PCR in the Detection of HBV-DNA Load. J China Med Univ 2005;34:341-343.

14 Kaplan C: The placenta and viral infection. Clin Obstet Gynecol 1990;33:232-241.

15 Douglas GC, Thirkill TL, Lasaell J: Automated quantitation of cell-mediated HIV type infection of human syncytiotrophoblast cells by fluorescence in situ hybridization and laser scanning cytometry. AIDS Res Hum Retroviruses 2001;17:507-516.

16 Lucifora G, Calabro S, Carraccio G, et al: Immunocytochemical HBsAg evidence in placenta sofa symptomatic carrier mothers. Am J Obstet Gynecol 1988;159:839-842.

17 Li F, Wang X, Men K, Xu D, Yan Y, Zhang $\mathrm{J}$ : Receptivity of human choriocarcinoma JEGIII cells and isolated trophoblast cells to hepatitis B virus infection and enhancement by tumor necrosis factor alpha. Jpn J Infect Dis 2007;60:167-172.

8 Arechavaleta-Velasco F, Koi, Strauss JF, Parry S: Viral infection of the trophoblast: time to take a serious look at its role in abnormal implantation and placentation? J Reprod Immunol 2002;55:113-121.

19 Lagaye S, Derrien M, Menu E, Coito C, Tresoldi E, Maucelre P, Scarlatti G, Chaouat G, Barre-Sinoussi F, Bomsel M, European Network for the Study of in utero Transmission of HIV-1: Cell-to-cell contact results in a selective translocation of maternal human immunodeficiency virus type 1 quasispecies across a trophoblastic barrier by both transcytosis and infection. J Virol 2001;75:4780-4791.
20 Koi H, Zhang J, Parry S: The mechanisms of placental viral infection. Ann NY Acad Sci 2001;943:148-156.

-21 Gabrielli L, Losi L, Varani S, Lazzarotto T, Eusebi V, Landini MP: Complete replication of human cytomegalovirus in explants of first trimester human placenta. Med Virol 2001;64:499-504.

22 Sureau C, Romet-Lemonne JL, Mullins J, et al: Production of hepatitis B virus by a differentiated human hepatoma cell line after transfection with cloned circular HBV DNA. Cell 1986;37-47.

23 Bchini R, Capel F, Dauguet C, et al: In vitro infection of human hepatoma (HepG2) cells with hepatitis B virus. J Virol 1990;64:30253032.

24 Chen Y, Sze J, He ML: HBV cccDNA in patients' sera as an indicator for $\mathrm{HBV}$ reactivation and an early signal of liver damage. World J Gastroenterol 2004;10:82-85.

25 Gao W, Hu J: Formation of hepatitis B virus covalently closed circular DNA: removal of genome-linked protein. J Virol 2007;81: 6164-6174.

26 Nassal M: Hepatitis B viruses: reverse transcription a different way. Virus Res 2008; 134:235-249.

27 Laras A, Koskinas J, Dimou E, Kostamena A, Hadziyannis SJ: Intrahepatic levels and replicative activity of covalently closed circular hepatitis B virus DNA in chronically infected patients. Hepatology 2006;44:694-702. 